\title{
$\bullet$ Antipsychotic Drugs Induced Movement Disorders: A Pharmacist Led Study
}

\author{
IJCRR \\ Section: Healthcare \\ ISI Impact Factor \\ (2019-20): 1.628 \\ IC Value (2019): 90.81 \\ $\operatorname{SJIF}(2020)=7.893$ \\ (c) (7) (8) \\ Copyright@IJCRR
}

\section{Jeena Jose ${ }^{1}$, Santosh Prabhu ${ }^{2}$, Nandakumar UP1, Sharad Chand ${ }^{1}$, Juno J. Joel ${ }^{1 *}$}

'Nitte (Deemed to be University), NGSM Institute of Pharmaceutical Sciences, Department of Pharmacy Practice, Deralakatte, Mangaluru, Karnataka, India; ${ }^{2}$ Department of Psychiatry, Justice K. S. Hegde Hospital, Deralakatte, Mangaluru, India.

\section{ABSTRACT}

Introduction: Drug-induced movement disorder is one of the major complications among patients undergoing antipsychotic drug therapy.

Objective: The study aims to assess the antipsychotic drugs induced movement disorders in hospitalized patients with psychiatric disorders.

Methods: A prospective observational study was carried out in a tertiary care teaching hospital for eight months. A total of 110 patients diagnosed with various psychiatric disorders and prescribed antipsychotic drugs were enrolled in the study. The movement disorders identified were documented and evaluated for causality assessment by using Naranjo's Algorithm and WHO Probability Scale. Severity was assessed by Modified Hartwig and Siegel scale and preventability was assessed by using Modified Schumock and Thornton's criteria. Data were analyzed by applying descriptive statistics.

Results: Out of 110 patients followed, 25 patients developed 25 incidents of movement disorders. It was found more among male patients. The incidence of Parkinsonism (40\%) was higher and was then followed by akathisia (32\%), dystonia (24\%) and tardive dyskinesia (4\%). Causality assessment reported the majority of adverse drug reactions (ADRs) as 'possible'. The severity assessment showed that $76 \%$ of the ADRs were moderately severe and $24 \%$ were mild reactions. The majority of the reactions were found probably preventable.

Conclusion: Antipsychotics are one of the major choices of drugs among psychiatric patients and they, in turn, can cause several adverse outcomes that can lead to a need for a modified therapeutic approach. Proper monitoring can prevent some possible and predictable adverse reactions.

Key Words: Psychiatry, Antipsychotics, Movement disorders, Causality assessment, Severity assessment.

\section{INTRODUCTION}

The drug-induced disorder is one of the major causes of hospitalization and poor therapeutic outcomes. ${ }^{1,2}$ Drug-induced disorders are adverse drug reactions. ${ }^{3}$ Antipsychotic drugs are meant for treating schizophrenia and other psychiatric disorders and their therapeutic efficacy is well established. Yet, many of these drugs have different side effect profiles. It is evidenced that second-generation antipsychotics have lesser effects when compared to first-generation antipsychotics. ${ }^{4,5}$ Ever since the antipsychotic effect of chlorpromazine was discovered there was an intense use of the drug. Within a short period, the parkinsonian side effects were identified. ${ }^{5,6}$ Akathisia is a type of disorder that involves motor restless- ness with discomfort especially in the limbs of the patient. These symptoms that appear in the initial stages of the therapy are more stressful and can lead to poor medication adherence. ${ }^{7}$ Similarly, it can happen with dystonia which is an involuntary movement disorder characterized by a recurrent spasm that subsequently leads to unusual movements or changing postures. ${ }^{8}$ Drug-induced parkinsonism is more common and causes considerable disability during maintenance treatment, most commonly in elderly patients. The patients may experience slow movements, flexed postures and soft speech. ${ }^{9}$ Tardive dyskinesia is also characterized by unusual involuntary movements but it reflects especially on the face and can vary in severity. ${ }^{10}$ The pharmacist-led study can identify the incidence of ADRs and other drug-related

\section{Corresponding Author:}

Dr. Juno J. Joel, Assistant Professor, Department of Pharmacy Practice, NGSMIPS, Nitte (Deemed to be University), Mangaluru, Karnataka, India-575018; Email: junojoel@nitte.edu.in

ISSN: 2231-2196 (Print)

Received: 31.08 .2020
ISSN: 0975-5241 (Online)

\author{
Revised: 07.11.2020
}

Accepted: 04.01 .2021
Published: 19.05 .2021 
problems. ${ }^{11,12}$ With this background the current study is focused on identifying the incidence of antipsychotic-induced movement disorders in a sample of patients with psychiatric disorders.

\section{MATERIALS AND METHODS}

A pharmacist-led prospective observational study was conducted for eight months. Institutional ethics committee approval was obtained before the initiation of the study. Informed consent was obtained from the patient/patient's party for taking a role in the study. All the inpatients of either gender aged above 18 years diagnosed with psychiatric disorders and prescribed with antipsychotics were included in the study. A suitable data collection form was designed to document the patient's age, gender, diagnosis, drug therapy details including drug, dose, duration of therapy and route of administration. These details were obtained from the patient's medical records. The enrolled patients were monitored daily. Any movement related disorders observed during the study was documented with the help of treating psychiatrists. The identified events were subjected to causality assessment using the WHO probability scale and Naranjo's scale. Severity was assessed by Modified Hartwig and Siegel scale and preventability by using Modified Schumock and Thornton's criteria. Descriptive statistical analysis was carried out using Statistical Package for Social Sciences.

\section{RESULTS}

\section{Patient characteristics}

Out of the total 110 patients enrolled in the study, $87(79.1 \%)$ were males and $23(20.9 \%)$ were females. The categorization according to the gender and various age groups of the patients is presented in Table 1 .

Table 1: Distribution of patients according to their gender and age

\begin{tabular}{lcccccc}
$\begin{array}{l}\text { Age } \\
\text { Group }\end{array}$ & $\mathbf{1 8 - 2 9}$ & $\mathbf{3 0 - 3 9}$ & $\mathbf{4 0 - 4 9}$ & $\mathbf{5 0 - 5 9}$ & $\mathbf{6 0 - 7 9}$ & Total \\
Male & 26 & 29 & 18 & 10 & 4 & 87 \\
Female & 5 & 8 & 3 & 4 & 3 & 23 \\
Total & 31 & 37 & 21 & 14 & 7 & 110 \\
\hline
\end{tabular}

\section{Distribution of the patients according to the psychiatric disorders}

Among the enrolled patients, the majority were diagnosed with paranoid schizophrenia 39 (35.5\%), followed by bipolar affective disorder $26(23.6 \%)$. The details are presented in Table 2
Table 2: Pattern of psychiatric disorders observed among the study population

\begin{tabular}{lcc} 
Types of disorders & $\begin{array}{c}\text { Frequency } \\
(\mathbf{n})\end{array}$ & $\begin{array}{c}\text { Percentage } \\
(\%)\end{array}$ \\
\hline Paranoid Schizophrenia & 39 & 35.5 \\
Bipolar affective disorders & 26 & 23.6 \\
Schizoaffective disorder & 17 & 15.5 \\
Psychosis & 14 & 12.7 \\
Undifferentiated schizophrenia & 6 & 5.5 \\
Post schizophrenic depression & 5 & 4.5 \\
Alcohol dependence syndrome & 2 & 1.8 \\
Nicotine dependence syndrome & 1 & .9 \\
Total & 110 & 100 \\
\hline
\end{tabular}

\section{Distribution of patients based on antipsychot- ics prescribed}

Overview of the antipsychotic drug prescriptions revealed that $82(74.5 \%)$ patients were prescribed with second-generation antipsychotics and $28(25.5 \%)$ patients received firstgeneration antipsychotics.

\section{Distribution of patients based on movement disorders identified}

In the study, $25(22.72 \%)$ patients reported a total of 25 incidents of movement disorders. The identified antipsychotic drug-related movement disorders were Parkinsonism, akathisia, dystonia and tardive dyskinesia. Details on the identified movement disorders are summarized in Figure 1.

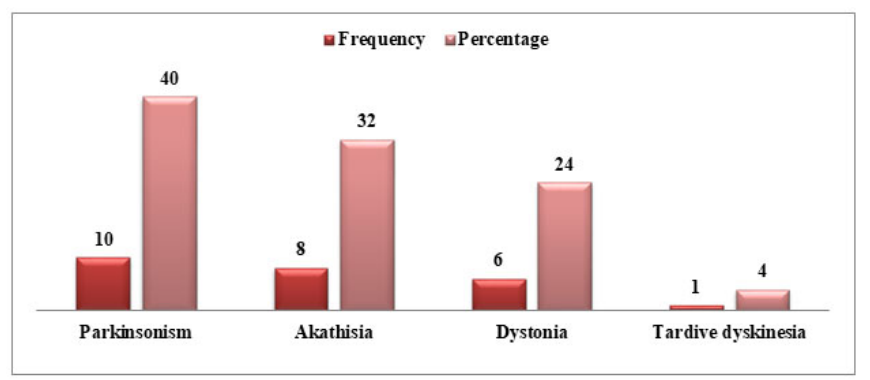

Figure 1: Distribution of different types of movement disorders among the patients.

\section{Categorization of study subjects with move- ment disorders based on their gender and age.} Out of the total 110 patients, 21 male and 4 female patients developed at least one type of movement disorder. The male patients showed a higher incidence of movement disorders when compared to females (Table 4). Patients belonging to the age group of 30-39 years were found to have the highest incidence of movement disorders (36\%). More details are summarized in Table 5. 
Table 4: Gender wise categorization of study subjects identified with movement disorders

\begin{tabular}{lcc} 
Gender & Presence & Absence \\
Male & $21(84 \%)$ & $66(77.6 \%)$ \\
Female & $4(16 \%)$ & $19(22.4 \%)$ \\
Total & 25 & 85 \\
\hline
\end{tabular}

Table 5: Age wise categorization of study subjects identified with movement disorders

\begin{tabular}{lccc} 
S1. No & $\begin{array}{c}\text { Age group (in } \\
\text { years) }\end{array}$ & Presence & Absence \\
& $18-29$ & $5(27 \%)$ & $26(30 \%)$ \\
& $30-39$ & $9(36 \%)$ & $28(32.9 \%)$ \\
& $40-49$ & $5(20 \%)$ & $16(18.8 \%)$ \\
& $50-59$ & $5(20 \%)$ & $9(10.6 \%)$ \\
& $60-79$ & $1(4 \%)$ & $6(7.1 \%)$ \\
Total & & 25 & 85 \\
\hline
\end{tabular}

Drugs suspected to cause movement disorders

In the present study, the movement disorders were found to be most commonly associated with the patients who received second-generation antipsychotics. The suspected secondgeneration antipsychotic drugs were quetiapine, risperidone, amisulpride, olanzapine and aripiprazole. Similarly, the suspected antipsychotic drugs of the first-generation included haloperidol and fluphenazine. Figure 2 summarizes the details of drugs responsible for movement disorders.

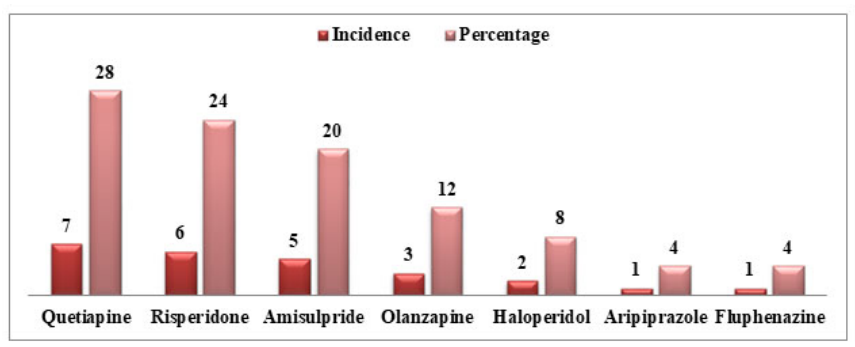

Figure 2: Suspected drugs responsible for movement disorders among the study subjects.

\section{Assessment on various types of movement disorders}

On a causality assessment based on the WHO probability scale, the majority of the movement disorders were found to be belonging to the category of possible 13 (52\%), followed by probable $10(40 \%)$. According to Naranjo's algorithm, it found that $12(48 \%)$ ADRs were possible and $11(44 \%)$ were probable. The severity assessment based on Modified Hartwig and Siegel scale showed that $19(76 \%)$ of the ADRs were moderately severe and $6(24 \%)$ were mild reactions. The majority of the reactions were found belonging to the severity Level 3 (10), followed by Level 4b (5), Level 2 and 4a (4 each) and Level 1 (2). As per Modified Schumock and Thornton's criteria, the majority of the ADRs were found to be probably preventable $20(80 \%)$, followed by definitely preventable, $5(20 \%)$

\section{Distribution of various movement disorders identified based on the suspected drugs}

The study evaluated various types of movement disorders based on the suspected antipsychotic drugs. The details are presented in Table 7.

\begin{tabular}{|c|c|c|c|}
\hline Sl. No & Drugs & Type of disorder & $\begin{array}{c}\text { Frequency } \\
(n=25)\end{array}$ \\
\hline 1. & Haloperidol & Akathisia & 2 \\
\hline 2. & Fluphenazine & Dystonia & 1 \\
\hline 3. & Aripiprazole & Parkinsonism & 1 \\
\hline 4. & Olanzapine & Akathisia & 3 \\
\hline \multirow[t]{4}{*}{5.} & \multirow[t]{4}{*}{ Quetiapine } & Parkinsonism & 4 \\
\hline & & Akathisia & 1 \\
\hline & & Dystonia & 2 \\
\hline & & Tardive dyskinesia & 1 \\
\hline \multirow[t]{2}{*}{6.} & \multirow[t]{2}{*}{ Risperidone } & Dystonia & 2 \\
\hline & & Parkinsonism & 3 \\
\hline \multirow[t]{3}{*}{7.} & \multirow[t]{3}{*}{ Amisulpride } & Akathisia & 2 \\
\hline & & Dystonia & 1 \\
\hline & & Parkinsonism & 2 \\
\hline
\end{tabular}

\section{DISCUSSION}

Movement disorders are one of the main adverse outcome associated with antipsychotic drug therapy. The current study showed that female patients were less when compared to males. Among these, 4 female and 21 male patients were presented with antipsychotic drug-induced movement disorders. The study conducted by Asif et al, also found that the male patients were more susceptible to drug-induced movement disorders like tardive dyskinesia and akathisia. ${ }^{13}$ Considering age-wise categorization of the study population, the current study found that out of 110 patients, the majority (33\%) belonged to the age group of $30-39$ years, $28 \%$ of patients were found to be in the age group of 18-29 years and $12 \%$ belonged to $40-59$ years. A previous study conducted by Cascade EF et al. showed that $24 \%$ were in the age group of $18-39$ years and $45 \%$ of patients belonged to $40-59$ years. ${ }^{14}$ Thus, there is a wide difference in the population when considering the age group. 
The most commonly diagnosed psychiatric disorders among the enrolled study subjects were paranoid schizophrenia which accounted for $39 \%$, followed by bipolar disorder. Whereas, in a study conducted by Sengupta et al, it was reported that bipolar disorder $(27 \%)$ were the most common diagnosis made, followed by schizophrenia (24\%). ${ }^{15}$ Antipsychotics are the primary drug of choice in the treatment of psychiatric illnesses. In this study, usage of the second generation $(74.5 \%)$ antipsychotics were found to be higher than the first-generation agents $(25.5 \%)$. The present study result was found similar to the study carried out by Meltzer et al, as second-generation antipsychotics were found to have a higher usage profile than the first generation. ${ }^{16}$ Among the various antipsychotic drugs prescribed, olanzapine accounted for the highest percentage (24.5\%). Similar findings were seen in the study conducted by Sengupta et al, in which olanzapine was found to be prescribed among $31.82 \%$ of the patients. ${ }^{15}$

Out of 25 identified movement disorders, the majority were suspected to be due to Quetiapine and risperidone drug therapy. Similar findings were seen in the study conducted by Piparva et al, which were among a total of 83 ADRs, the majority were caused due to risperidone and olanzapine. ${ }^{17}$ The possibility of antipsychotics induced dystonia is common among patients with psychiatric disorders. Antipsychotics induced movement disorders are a common issue associated with the therapy. The antipsychotics show a higher rate of adverse reactions in patients undergoing therapy where the movement disorder is considered to be the major one. In this study, it was observed that $22 \%$ of the patients developed movement related disorders. Among these, parkinsonism and akathisia showed a higher rate of incidence with the percentage of $40 \%$ and $32 \%$ respectively, followed by dystonia $24 \%$, and tardive dyskinesia $4 \%$. The previous study conducted by Janno et al, reported that $61 \%$ of the patients were presented with antipsychotic drug-induced movement disorders with a high incidence of akathisia $31.3 \%$, followed by parkinsonism 24\% and tardive dyskinesia 32\%. ${ }^{18}$ The present study results were in association with the previous study suggests that the incidence of akathisia and parkinsonism could be higher than other antipsychotic drug-induced movement disorders. In this study, the occurrence of dystonia was noted to be $24 \%$ among all the other identified movement related disorders. A study conducted by Addonizio G et al. reported that $31 \%$ of patients developed dystonia during antipsychotic therapy. ${ }^{19}$ These reports were found to be comparable with the present study.

\section{CONCLUSION}

The study established the incidence of various types of antipsychotics induced movement disorders in this sample population. Antipsychotics are one of the major choices of drugs in the management of psychiatric conditions and they, in turn, can cause several adverse outcomes that can lead to a need for a modified therapeutic approach. The current study reported Quetiapine and Risperidone as the major suspected drugs that caused movement related disorders. The commonly encountered movement disorders were parkinsonism, akathisia and dystonia. Causality analysis based on Naranjo's scale and WHO scale evidenced that the majority of movement disorders had a possible relationship with the suspected drug. The preventability assessment showed that the majority of the reactions were probably preventable. With these reports, the study suggests that the incidence of movement-related disorders can be controlled by regularly monitoring the patients who are prescribed antipsychotics that are found to have a higher risk of developing such adverse effects.

FUNDING: This work did not receive any financial support from any organization or funding agencies.

\section{ACKNOWLEDGMENT}

We Authors are thankful to the Department of Psychiatry, Justice K. S. Hegde, Charitable Hospital, Nitte (Deemed to be University) for their support during the study.

Conflict of Interest: There is no conflict of interest

\section{REFERENCES}

1. Chand S, Bhandari R, Girish HN, Sukeerthi D, Sah SK, Voora L. Isoniazid induced psychosis. J Global Pharma Tech 2019;11(5):11-14.

2. Rachana J, Shastry CS, Mateti UV, Sharma R, Nandakumar UP, Chand $\mathrm{S}$. Incidence and associated factors of adverse drug reactions in the general medicine department of a tertiary care teaching hospital. Int J Pharmac Res 2019;11(3):177-184.

3. Kurian A, Babu B, Punnoose B, Chacko CS, Rao M, Chand S, et al. Cisplatin-induced peripheral neuropathy: an observational descriptive study. Int J Res Pharm Sci 2020;11(03):3585-3589.

4. Barnes TRE, McPhillips MA. Critical analysis and comparison of the side effects and safety profiles of the new antipsychotics. Br J Psychiatry 1999;174(suppl 38):34-43

5. Rawal KB, Chand S, Luhar MB. A comparative study on relative safety and efficacy of chlorpromazine and risperidone. Int J Res Pharmac Sci 2020;11(02):1539-1544.

6. Hall, RA, Jackson, RB, Swain, JM. Neurotoxic reactions resulting from chlorpromazine administration. JAMA 1956;161(3): 214-218.

7. Halstead SM, Barnes TRE, Speller JC. Akathisia: Prevalence and associated dysphoria in an in the patient population with chronic schizophrenia. Br J Psychiatry 1994;164:177-83.

8. Satterthwaite TD, Wolf DH, Rosenheck RA, Gur RE, Caroff SN. A meta-analysis of the risk of acute extrapyramidal symptoms with intramuscular antipsychotics for the treatment of agitation. J Clin Psychiatry 2008;69(12):1869-1879.

9. Tarsy D. neuroleptic-induced extrapyramidal reactions: classification, description, and diagnosis. Clin Neuropharmacol 1983;6(1):S9-26 
10. Blanchet PJ. Antipsychotic drug-induced movement disorders. Can J Neurol Sci 2003;30(1): S101-7.

11. Roy DA, Shanfar I, Shenoy P, Chand S et al. Drug-related problems among chronic kidney disease patients: A pharmacist-led study. Int J Pharmac Res 2020;12(04):79-84.

12. Voora L, Sah SK, Bhandari R, Shastry CS, Chand S, Rawal KB, Nandakumar UP, Vinay BC. Doctor of pharmacy: boon for the healthcare system. Drug Invention Today 2020;14(1):53-158.

13. Asif U, Saleem Z, Yousaf M. Gender wise clinical response of antipsychotics among schizophrenic patients: A prospective observational study from Lahore, Pakistan. Int J Psychiatry Clin Pract 2017;22(3):177-183.

14. Cascade EF, Karali AH, Citrome L. Antipsychotic use vary by patient age. Psychiatry (Edgmont). 2007;4(7):20-23.
15. Sengupta G, Bhowmick S, Hazra A, Datta A, Rahaman M. Adverse drug reaction monitoring in psychiatry out-patient department of an Indian teaching hospital. Indian J Pharmacol 2011; 43(1):36.

16. Meltxer DO, Basu A, Meltzer HY. Comparative effectiveness research for antipsychotic medications; How much is enough? Health Affairs 2009;28(5):794-808.

17. Piparava KG, Buch JG, Chandhrani KV. Analysis of adverse drug reactions of atypical antipsychotic drugs in psychiatry OPD. Indian J Psychol Med 2011;33(2):153.

18. Janno S, Holi M, Wahlbeck K. prevalence of nueroleptic induced movement disorders in chronic schizophrenic inpatients. Am J Psychiatry 2004;161(1):160-163.

19. Addonizio G, Alexopoulos GS. Drug-induced dystonia in young and elderly patients. Am J Psychiatry 1988;145(7):869. 